\title{
Ocular Causes of Headache in Patients Presenting To a Sub- Urban Eye Hospital
}

\author{
Sanket Parajuli ${ }^{1 *}$, Ruchi Shrestha ${ }^{1}$, Senny Chapagain ${ }^{1}$, Ramesh Shrestha ${ }^{1}$, Prerana Singh ${ }^{1}$, Sarmila \\ Acharya $^{1}$ \\ ${ }^{1}$ Reiyukai Eiko Masunaga eye hospital, Banepa, Nepal \\ *Corresponding Author: Sanket Parajuli, Reiyukai Eiko Masunaga eye hospital, Banepa, Nepal, \\ Email: sanketparajuli@gmail.com
}

Received Date: 04-03-2021; Accepted Date: 25-03-2021; Published Date: 01-04-2021

Copyright $^{\circledR} 2021$ by Parajuli S, et al. All rights reserved. This is an open access article distributed under the terms of the Creative Commons Attribution License, which permits unrestricted use, distribution, and reproduction in any medium, provided the original author and source are credited.

\begin{abstract}
Background: Headache is one of the most frequent complaints for which the patients visit the medical practitioners. The current study was planned to determine the aetiology of headache in patients seen for an ocular examination in ophthalmology outpatient clinics in a Sub-Urban Eye Hospital.

Methods: This is a cross-sectional study conducted in Reiyukai Eiko Masunaga Eye Hospital, Banepa, Nepal over a period of 3 months from 1st March 2020 to 1st June 2020. 200 patients with headache with or without ocular pain were enrolled in the study. The patients were assessed for any ocular cause of headache.

Results: Of the 200 patients, $115(57.5 \%)$ were female and $85(42.5 \%)$ were male. The overall mean age was 37.19 years (range: 11-65 years). 69 of 200 patients had refractive error (34.5\%).Most common error was astigmatism (69.5\%) followed by myopia (17.3\%) and hyperopia (13.05\%). 58(29\%) patients were above the age of 40 years and hence were presbyopic $14 \%$ had convergence insufficiency, $4.2 \%$ had accommodation insufficiency and $3.5 \%$ had fusional insufficiency various ocular morbidities that were noted were corneal ulcer, disciform keratitis, epithelial defect, primary angle closure glaucoma, phacomorphic glaucoma, primary angle closure suspect, chronic angle closure, ocular hypertension, anterior uveitis , posterior scleritis, optic neuritis, intracranial space occupying lesion indicated by papilledema, acute dacryocystitis, herpes zoster ophthalmicus , preseptal cellulitis and painful internal hordeolum.
\end{abstract}


Conclusion: A detailed evaluation of patient with headache is necessary to properly identify and treat the cause of headache. The role of ophthalmologist in assessing the patients with headache has been emphasized by this study.

\section{Keywords}

Headache, Ocular Causes of Headache, Ocular Implications in Headache

\section{Introduction}

Headache, defined as the pain located above orbito-meatal line, is one of the most common disorders worldwide [1]. Headache not only impairs the job productivity but also reduces the quality of life. It's one of the most frequent complaints for which the patients visit the medical practitioners [2]. Nearly half to three quarters of adults of age ranging from 18-65 years have had an episode of headache in the previous year [3]. Refractive errors are often associated with frontal and/or occipital headache [4]. Asthenopia is said to be dull aching or boring pain, whether superficial or deep-seated, constant or intermittent, especially related to the use of eyes and aggravated by factors such as fatigue or poor illumination [5]. There is usually ocular discomfort with lids feeling hot and swollen. Vision may be blurred, particularly for near work. Frontal headache may develop. In asthenopia the eyes appear normal but on examination may reveal refractive errors, accommodative fatigue, poor convergence or difficulty in controlling a latent squint. So asthenopia should be ruled out whenever headache is a presenting complain [4]. The mechanism of headache associated with asthenopia is not fully understood but it is presumed to be on the basis of referred pain of visceral origin. So ciliary pain is referred to areas associated with cervical segments which connect with the superior cervical ganglion and the somatic outflow from which is represented by bulbospinal root of trigeminal and upper cervical nerves. As ophthalmic division of trigeminal nerve is represented most caudally, ciliary pain is primarily frontal and occipital in origin [6]. Untreated hyperopia can result in persistent attempts to accommodate, thus relaxing accommodation with hyperopic prescription may lessen the eye discomfort. Accommodative spasm usually occurs in young patients and presents with eye pain, myopia and meiosis when doing near work [7-11].

An observational study conducted among 202 patients in India prevalence of refractive errors in headache patients was $1.48 \%$ [6]. Also in a study carried out among 1400 patients attending for refraction, $45 \%$ complained of headache [7]. Gordon, et al., found that minor refractive error (especially hyperopia) often caused more headache and symptoms of eyestrain than major refractive error [8]. The role of different ocular diseases like acute glaucoma, uveitis, optic neuritis and visual anomalies like refractive errors and accommodative and vergence deficiencies in headache are most important from ophthalmological point of view [9]. Acute elevation in intraocular pressure is usually associated with pain, while an eye with a similar pressure of gradual onset may be asymptomatic. While acute angle-closure glaucoma is the most common painful glaucoma, some forms of secondary open- and closed-angle glaucoma

Parajuli S | Volume 2; Issue 1 (2021) | JOAR-2(1)-010 | Research Article

Citation: Parajuli S, et al. Ocular Causes of Headache in Patients Presenting To a Sub-Urban Eye

Hospital. J Ophthalmol Adv Res. 2021;2(1):1-9.

DOI: http://dx.doi.org/10.46889/JOAR.2021.2105 
are associated with acute pressure spikes and pain [10]. Apart from the ocular morbidities mentioned above, other pathologies that are often seen to be associated with headache in ophthalmic practice are Herpes Zoster Ophthalmicus (HZO), Painful $3^{\text {rd }}$ nerve palsy, Cavernous sinus thrombosis, papilledema, Necrotising or non-necrotising scleritis, orbital wall fracture with extraocular muscle impingement. Papilloedema often warrants urgent neuroimaging to rule out tumour, hydrocephalus or bleeding. The headache of increased intracranial pressure need not be severe, but it is often present on awakening and associated with vomiting. The ophthalmologist should not consider this entity benign, as chronic papilloedema may lead to blindness [11].

There is an array of diseases which presents with headache in ophthalmology clinic placing the ophthalmologist in the front line of their recognition and management. The current study was planned to determine the aetiology of headache in patients seen for an ocular examination in ophthalmology outpatient clinics in a sub urban Eye hospital.

\section{Methods}

\section{Patients}

This is a cross-sectional study conducted in Reiyukai Eiko Masunaga Eye Hospital, Banepa, Nepal over a period of 3 months from $1^{\text {st }}$ March 2020 to $1^{\text {st }}$ June 2020. Ethical approval was obtained from the local ethical committee. The hospital covers a large population of approximately 2.5 million people from Kavrepalanchowk, Sindhu-palchowk, Dolakha, Sindhuli, Ramechhap, Bhaktapur, kathmandu and other surrounding districts. This hospital targets mainly the people with low to mid socio-economic status. Every $3^{\text {rd }}$ patient who presented to the hospital with complains of headache with or without ocular pain were included in the study. Full informed consent was obtained and participants were able to abstain or withdraw from the research at any time without having to give a reason. No participants withdrew after they had arrived at the clinic. All patients underwent a detailed ocular examination which included Visual acuity, refraction, orthoptic evaluation and detailed slit lamp examination. Investigations included intraocular pressure of all patients and visual field examination with automated visual field perimetry (OCULUS) in patients where it would aid in diagnosis.

\section{Sample Size}

Prevalence of headache from a nationwide study in Nepal has shown the prevalence to be 85.6\%. [12] Using formula $\mathrm{n}=[\mathrm{z} 2 \mathrm{p}(1-\mathrm{P})] / \mathrm{d} 2$ where $\mathrm{n}$ is sample size, $\mathrm{z}$ is standard variate (1.96), $\mathrm{p}$ is prevalence $(85.6 \%), \mathrm{d}$ is standard of error(0.05)

$[(1.96) 2 * 0.85 *(1-0.85)] /(0.05) 2=195.9$

200 was taken as the sample size for the study. 


\section{Assessments}

Assessment included demographic data (e.g. sex, age, and occupation), onset and characteristics of headache, diurnal variation of headache (categorized into morning, afternoon, evening, during the night, or none), site of pain (back, front, left sided, right sided or diffuse), associated symptoms, aura were assayed, aggravating factors (including physical or visual effort), family history, history of trauma, dental caries, sinusitis. Visual acuity assessment was done for each eye and near vision was recorded at a distance of $33 \mathrm{~cm}$ with good illumination with Snellen's near vision Chart. Refractive status of patients was assessed. Patients under 15 years of age underwent cycloplegic retinoscopy with $1 \%$ cyclopentolate. Patients with refractive error $>+0.50 \mathrm{D}$ were considered as hyperopia and those with error $>-0.50 \mathrm{D}$ were considered as myopia. Astigmatism was defined as the cylindrical component of the refractive error more than $0.50 \mathrm{D}$. Orthoptic assessment included, cover tests (at both near and far fixation), near Point of Convergence (NPC), Amplitude of Accommodation (AA) both measured using a Royal Air Force (RAF) ruler, and fusional reserves (using vertical prisms). Slit lamp bimicroscopy and detailed fundus examination were carried out to rule out ocular pathology. Intraocular pressure was measured with Goldmann tonometer on all the patients. Statistical software 'Statistical Package for Social Sciences, version-25 was used to analyze data.

\section{Results}

Out of the 200 patients, $115(57.5 \%)$ were female and $85(42.5 \%)$ were male. The overall mean age was 37.19 years (range: 11-65 years) (Table 1).

\begin{tabular}{|c|c|c|c|}
\hline \multirow{2}{*}{ Age Group } & \multicolumn{2}{|c|}{ Gender } & Total N (\%) \\
\cline { 2 - 4 } & Males N (\%) & Females N (\%) & \\
\hline$<20$ years & $23(11.5 \%)$ & $14(7 \%)$ & $37(18.5 \%)$ \\
\hline $\begin{array}{c}\text { 20-39 years } \\
\text { (Non presbyopic adults) }\end{array}$ & $41(20.5 \%)$ & $64(32 \%)$ & $105(52.5 \%)$ \\
\hline $\begin{array}{c}40 \text { and above } \\
\text { (Presbyopic) }\end{array}$ & $21(10.5 \%)$ & $37(18.5 \%)$ & $58(29 \%)$ \\
\hline Total & $85(42.5 \%)$ & $115(57.5 \%)$ & $200(100 \%)$ \\
\hline
\end{tabular}

Table 1: Age group and gender distribution among patients.

The most common site of headache was frontal region $(36.5 \%)$ followed by headache in occipital region $(30 \%)$. Other sites of headache noted were diffuse $(14.5 \%)$, temporal $(7.5 \%)$ and hemicranial type (6\%) (Table 2). 


\begin{tabular}{|c|c|c|c|c|c|c|c|}
\hline Age group & $\begin{array}{c}\text { Frontal } \\
\mathbf{N}(\%)\end{array}$ & $\begin{array}{c}\text { Occipital } \\
\mathbf{N}(\%)\end{array}$ & $\begin{array}{c}\text { Hemicranial } \\
\mathbf{N}(\%)\end{array}$ & $\begin{array}{c}\text { Temporal } \\
\mathbf{N}(\%)\end{array}$ & $\begin{array}{c}\text { Diffuse } \\
\mathbf{N}(\%)\end{array}$ & $\begin{array}{c}\text { Non-localized } \\
(\text { vague } \mathbf{N}(\boldsymbol{\%})\end{array}$ & $\begin{array}{c}\text { Total } \\
\mathbf{N}(\%)\end{array}$ \\
\hline$<20$ years & $18(9 \%)$ & $10(5 \%)$ & $1(0.5 \%)$ & $1(0.5 \%)$ & $5(2.5 \%)$ & $2(1 \%)$ & $37(18.5 \%)$ \\
\hline $20-39$ years & $\begin{array}{c}41 \\
(20.5 \%)\end{array}$ & $26(13 \%)$ & $6(3 \%)$ & $6(3 \%)$ & $18(9 \%)$ & $8(4 \%)$ & $\begin{array}{c}105 \\
(52.5 \%)\end{array}$ \\
\hline $\begin{array}{c}40 \text { and } \\
\text { above }\end{array}$ & $14(7 \%)$ & $24(12 \%)$ & $5(2.5 \%)$ & $8(4 \%)$ & $6(3 \%)$ & $1(0.5 \%)$ & $58(29 \%)$ \\
\hline Total & $\begin{array}{c}73 \\
(36.5 \%)\end{array}$ & $60(30 \%)$ & $12(6 \%)$ & $15(7.5 \%)$ & $\begin{array}{c}29 \\
(14.5 \%)\end{array}$ & $11(5.5 \%)$ & $200(100 \%)$ \\
\hline
\end{tabular}

Table 2: Site of headache.

$88 \%$ had vision better than $6 / 12$ in Snellen's acuity chart, $9 \%$ had vision $6 / 12$ to $6 / 60$ and $3 \%$ had vision worse than $6 / 60$ (Table 3 ).

\begin{tabular}{|l|l|}
\hline Best corrected Visual acuity & Frequency n (\%) \\
\hline Better than 6/12 & $176(88 \%)$ \\
\hline $6 / 12-6 / 60$ & $18(9 \%)$ \\
\hline Worse than $6 / 60$ & $6(3 \%)$ \\
\hline
\end{tabular}

Table 3: Visual acuity and refractive errors.

69 of 200 patients had refractive error (34.5\%). Most common error was astigmatism $(69.5 \%)$ followed by myopia (17.3\%) and hyperopia (13.05\%). 58(29\%) patients were above the age of 40 years and hence were presbyopic. BSV was assessed only in patients less than 40 years of age and it was found that $14 \%$ had convergence insufficiency, $4.2 \%$ had accommodation insufficiency and $3.5 \%$ had fusional insufficiency. $1(0.7 \%)$ patient was found to have intermittent exotropia (Table 4).

\begin{tabular}{|l|l|}
\hline Causes of Asthenopia & Frequency (\%) \\
\hline Refractive error & $48(69.5 \%)$ \\
\hline Astigmatism & $12(17.3 \%)$ \\
\hline Myopia & $9(13.0 .5 \%)$ \\
\hline Hyperopia & $69(34.5 \%)$ \\
\hline Total refractive error & $\begin{array}{l}\mid \\
\text { Orthoptic abnormalities(BSV deficits) [only in non presbyopic patients]- after full refractive } \\
\text { correction }\end{array}$ \\
\hline Convergence insufficiency & $14(9.8 \%)$ \\
\hline Accommodation insufficiency & $6(4.2 \%)$ \\
\hline Fusional insufficiency & $5(3.5 \%)$ \\
\hline Intermittent exotropia & $1(0.7 \%)$ \\
\hline Total BSV abnormalities & $26(18.3 \%)$ \\
\hline Presbyopia & $58(29 \%)$ \\
\hline Computer vision syndrome & $45(22.5 \%)$ \\
\hline
\end{tabular}

Table 4: Causes of asthenopia. 
Various ocular morbidities that were noted in patients and were possibly the cause of headache were as follows, corneal ulcer $(3.5 \%)$, disciform keratitis $(6 \%)$, epithelial defect $(0.5 \%)$, primary angle closure glaucoma $(0.5 \%)$, phacomorphic glaucoma $(1 \%)$, primary angle closure suspect $(1 \%)$, Chronic angle closure $(0.5 \%)$, ocular hypertension $(6 \%)$, anterior uveitis $(4.5 \%)$, posterior scleritis $(1 \%)$, optic neuritis $(1 \%)$, intracranial space occupying lesion indicated by papilledema $(1 \%)$, acute dacryocystitis $(1 \%)$, herpes zoster ophthalmicus $(0.5 \%)$, preseptal cellulitis (1\%) and painful internal hordeolum (1\%) (Table 5).

\begin{tabular}{|c|c|}
\hline \multicolumn{2}{|l|}{ Ocular Morbidities in Headache } \\
\hline \multicolumn{2}{|l|}{ Cornea } \\
\hline Corneal ulcer & $7(3.5 \%)$ \\
\hline Disciform keratitis & $12(6 \%)$ \\
\hline Epithelial defect & $1(0.5 \%)$ \\
\hline \multicolumn{2}{|l|}{ Glaucoma } \\
\hline Primary Angle closure glaucoma & $1(0.5 \%)$ \\
\hline Phacomorphic glaucoma & $2(1 \%)$ \\
\hline Primary angle closure suspect & $2(1 \%)$ \\
\hline Chronic angle closure & $1(0.5 \%)$ \\
\hline Ocular hypertension & $12(6 \%)$ \\
\hline \multicolumn{2}{|l|}{ Uvea } \\
\hline Anterior Uveitis & $9(4.5 \%)$ \\
\hline Posterior Scleritis & $2(1 \%)$ \\
\hline \multicolumn{2}{|l|}{ Neuro-ophthalmology } \\
\hline Optic neuritis & $2(1 \%)$ \\
\hline Intracranial space occupying lesion (Papilledema) & $2(1 \%)$ \\
\hline \multicolumn{2}{|l|}{ Miscellaneous } \\
\hline Acute dacryocystitis & $2(1 \%)$ \\
\hline Herpes zoster ophthalmicus & $1(0.5 \%)$ \\
\hline Preseptal cellulitis & $2(1 \%)$ \\
\hline Internal hordeolum & $2(1 \%)$ \\
\hline \multicolumn{2}{|l|}{ Non Ocular Causes } \\
\hline Migraine & $4(2 \%)$ \\
\hline Sinusitis & $2(1 \%)$ \\
\hline No ocular abnormalities identified & $13(6.5 \%)$ \\
\hline
\end{tabular}

Table 5: Ocular causes of headache apart from asthenopia.

\section{Discussion}

One of the most frequently encountered complain by any ophthalmologist is headache with or without ocular pain. As important it is to treat the condition with analgesics, it is equally important to identify the associated condition leading to headache in these patients. The primary causes range from non-lethal causes like refractive errors to potentially life-threatening 
condition like intracranial space occupying lesion. This study emphasizes on the point that all patients with headache should be examined thoroughly to prohibit possible complications.

Asthenopia, or eye strain, was a major entity in this study. 69(34.5\%) patients with asthenopia had refractive error. One of the French study conducted in patients with headache reported $44 \%$ refractive errors [13]. A Nepalese study conducted a similar study where $44 \%$ of the patients had refractive errors among whom astigmatism was more frequent $(63.63 \%)$ followed by hyperopia (27.27\%) and myopia (9.09\%) [14]. This was similar to our study as astigmatism $(69.5 \%)$ was the most common type of error followed by myopia $(17.3 \%)$ and hyperopia (13.05\%). In a study by Gil Gouveia and Martins it was reported that $72.5 \%$ of the subjects reported improvement in their headache, and 38\% had complete remission of headache after refractive correction [15]. Another cause of asthenopia was presbyopia. The number of presbyopics with complaint of headache was 58 (29\%). Kimbo, et al., reported $11 \%$ patients of presbyopia in their study who presented with complaint of headache [13]. The prevalence of presbyopia in our study is high because most of the visiting patients were older citizens. Also our center primarily targets old population for eye diseases thus the average patients are usually old aged people. The prevalence of headache among computer users observed in another study was $22.5 \%$ [14]. The greater use of computers and mobile devices was primarily due to the lockdown imposed during the study duration as a result of COVID 19 pandemic. The schools and colleges were shut down giving the younger population ample amount of time to engage in mobile gaming and computer use. The pathophysiology of headache associated with prolonged computer use resides within the ocular surface abnormalities, accommodative spasms and dry eyes [16].

Among other ocular causes of headache, patients with corneal ulcers were $3.5 \%$. Primary angle closure glaucoma was seen in $0.5 \%$ patients, phacomorphic glaucoma in $1 \%$, primary angle closure suspect in $1 \%$, chronic angle closure in $0.5 \%$, ocular hypertension in $6 \%$, anterior uveitis in $4.5 \%$, posterior scleritis in $1 \%$ of individuals. Kimbo, et al., in his study has mentioned $12 \%$ patients with anterior segment disease such as glaucoma and uveitis had headache [13]. Any ocular inflammatory disease and acute rise in intraocular pressure may cause pain in and around the eye and also cause headache [4]. Disciform keratitis (6\%), epithelial defect $(0.5 \%)$, optic neuritis $(1 \%)$, acute dacryocystitis $(1 \%)$, herpes zoster ophthalmicus $(0.5 \%)$, preseptal cellulitis $(1 \%)$ and painful internal hordeolum $(1 \%)$ were other causes that were noted in this study. Intracranial space occupying lesion indicated by papilledema was reported in $2(1 \%)$ cases in our study and were referred for CT scan of head and orbit to rule out space occupying lesion. Headache from elevated blood pressure may also be accompanied by bilateral disk swelling [17]. In the current study, 2(1\%) cases of reterobulbar optic neuritis was also reported to have headache. Retrobulbar optic neuritis usually presents with sudden diminution of vision and retrobulbar pain on eye movement [18]. A few cases of stye, infected chalazion, pterygium and orbital cellulitis were also reported, which present with headache as an associated symptom. Migraine was the cause of headache in $4(2 \%)$ patients. Migraine represents more than half of headaches. Migraine with aura, also called classic migraine constitutes $10-35 \%$ of migraines. The exact mechanism which occurs during a migraine is unknown. Some evidence suggests a role for central nervous system

Parajuli S | Volume 2; Issue 1 (2021) | JOAR-2(1)-010 | Research Article

Citation: Parajuli S, et al. Ocular Causes of Headache in Patients Presenting To a Sub-Urban Eye

Hospital. J Ophthalmol Adv Res. 2021;2(1):1-9.

DOI: http://dx.doi.org/10.46889/JOAR.2021.2105 
mediators and vasodilatation [1]. Kimbo, et al., had 3.9\% of patients in his study who presented with headache diagnosed as migraine [13]. Cluster Headache $(\mathrm{CH})$ is characterized by recurrent, severe headache on one side of the head, typically around the eye [19]. No patient in our study reported with cluster headache. Sinusitis was reported in $2(1 \%)$ patients. A clinical study of headache and sinusitis by A Kaur., reported $28.9 \%$ patients with sinusitis had complains of headache. Patients with sinus headaches usually complain of pain and pressure sensation around the sinuses and peri-orbital areas [20].

In 13 of the patients $(6.5 \%)$ no any ocular pathology could be identified that could possibly be the cause of headache. Since the patients were only examined by an ophthalmologist medical causes of headache like migraine (atypical), chronic hypertension, tobacco use may have been missed. This is also the noteworthy limitation of our study. A better study would be to include patients with headache where all systemic causes have been ruled out. Another limitation is that during the study duration, COVID pandemic led to lockdown which increased the use of computers and mobile device usage. This might have increased the number of patients with headache associated with computer use which would otherwise be low.

\section{Conclusion}

A detailed evaluation of patient with headache is necessary to properly identify and treat the cause of headache. Also the role of ophthalmologist in assessing the patients with headache has been emphasized by this study.

\section{Declarations}

Ethics approval and consent to participate: Approved by local ethical committee (ERB/REH 20/01), written informed consent from all participants were obtained.

\section{References}

1. Olesen J, Bes A, Kunkel R, Lance J, Nappi G, Pfaffenrath V, et al. The international classification of headache disorders. $2^{\text {nd }}$ ed. Headache classification subcommittee of the international headache society: Blackwell Publishing. Cephalalgia. 2004;24:150.

2. Harle DE, Evans BJW. The correlation between migraine headache and refractive errors. Optom Vis Sci. 2006;83:82-7.

3. Atlas of headache disorders and resources in the world 2011.

4. Roger L, Patrick J. Head and facial pain. In: Outline of Ophthalmology. British: JohnWright and Sons Ltd. 1985:64-5.

5. David A. Clinical Importance of Refraction. In: Duke-Elder's practice of refraction. London: Churchill Livingstone. 1978.3-5.

6. Jain AP, Chauhan B, Bhat AD. Sociodemographic and clinical profile of headache-a rural hospital-based study. Indian Acad Clin Med. 2007;8:26-8.

7. Whittington TD. The art of clinical refraction. London: Oxford University Press. 1958.

8. Gordon DM. Some headaches in an ophthalmologist's office. Headache. 1966;6:141-6. 
9. Daroff RB. Ocular causes of headache. Headache. 1998;38:661.

10. Martin TJ, Soyka D. Ocular causes of headache. Olesen J, Tfelt-Hansen P, Welch KMA W (Eds) The headaches. Raven Press, New York. 1993;748-52.

11. Fasih U, Shaikh A, Shaikh N. Aetiology of headache in clinical ophthalmic practice at a tertiary care hospital of Karachi. J Pak Med Assoc. 2017;67(2):166-70.

12. Manandhar K, Risal A, Steiner TJ, Holen A, Linde M. The prevalence of primary headache disorders in Nepal: a nationwide population-based study. J Headache Pain. 2015;16:95.

13. Kimbo DK, Misotten L. Headaches in ophthalmology. J Fr Ophtalmol. 2003;26:143-7.

14. Marasini S, Khadka J, Sthapit PRK, Sharma R, Nepal BP. Ocular morbidity on headache ruled out of systemic causes-A prevalence study carried out at a community based hospital in Nepal. J Optom. 2012;5:68-74.

15. Gil-Gouveia R, Martins IP. Headaches associated with refractive errors: myth or reality? Headache 2002;42:256-62.

16. Blehm C, Vishnu S, Khattak A, Mitra S, Yee RW. Computer vision syndrome: a review. Surv Ophthalmol. 2005;50:253-62.

17. Johnson LN, Krohel GB, Madsen RW, March GA. The role of weight loss and acetazolamide in the treatment of idiopathic intracranial hypertension (pseudotumor cerebri). Ophthalmol. 1998;105:2313-7.

18. Lepore FE. The origin of pain in optic neuritis. Determinants of pain in 101 eyes with optic neuritis. Arch Neurol. 1991;48:748-9.

19. Weaver-Agostoni J. Cluster headache. Am Fam Physician. 2013;88:122-8.

20. Kaur A, Singh A. Clinical study of headache in relation to sinusitis and its management. J Med Life. 2013;6:389-94. 